\title{
The Effects of Macroeconomic Indicators on Economic Growth of Nigeria (1970-2015)
}

\author{
Mustapha Abiodun Okunnu ${ }^{1}$, Matthew Iwada Ekum ${ }^{2,}$, Oluwaseun Raphael Aderele ${ }^{2}$ \\ ${ }^{1}$ Department of General Studies (Economics Division), School of Communication \& Liberal Studies, Lagos State Polytechnic, Lagos, \\ Nigeria \\ ${ }^{2}$ Department of Mathematics \& Statistics, School of Pure \& Applied Science, Lagos State Polytechnic, Lagos, Nigeria
}

\section{Email address:}

biodunokunnu@gmail.com (M. A. Okunnu),matekum@yahoo.com (M. I. Ekum), aderele.or@gmail.com (O. R. Aderele)

${ }^{*}$ Corresponding author

\section{To cite this article:}

Mustapha Abiodun Okunnu, Matthew Iwada Ekum, Oluwaseun Raphael Aderele. The Effects of Macroeconomic Indicators on Economic Growth of Nigeria (1970-2015). American Journal of Theoretical and Applied Statistics. Vol. 6, No. 6, 2017, pp. 325-334. doi: $10.11648 / j$.ajtas.20170606.19

Received: March 21, 2017; Accepted: April 10, 2017; Published: December 24, 2017

\begin{abstract}
According to World Bank statistics reported in 2016, the Gross Domestic Product per capita (RGDP) in Nigeria was 2,548.20 United States Dollar (USD) in 2015. Also, Nigeria's highest ever GDP recorded was 568.508 billion USD in 2014, with this exceptional growth in the economy, the World Bank and National Bureau of Statistics (NBS) and Central Bank of Nigeria (CBN) forecast GDP for 2016 to be very high but unfortunately, the GDP published by NBS and CBN as at June 2016 was 22.26 billion USD, which was the lowest ever since returning to democracy in 1999. This sharp fall in GDP reduced Nigeria GDP per capita drastically. It is based on this we employed Dynamic Multiple Linear Regression Model to fit a model of RGDP of Nigeria using some world development indicators as explanatory variables. Data was collected from 1970 to 2015 from World Bank database and National Bureaus of Statistics (NBS) on the six World Development Indicators (WDI), total Import, official exchange rate, broad money, inflation rate, total natural resources rents and foreign direct investment. The dynamic weighted least square (DWLS) was used rather than the dynamic ordinary least square (DOLS). The result of the analysis shows that imports of goods and services positively affect RGDP of Nigeria significantly, while other explanatory variables negatively affect RGDP significantly. Based on this result, we recommend that rather than closing boarder to imports of goods and services, we need to restructure the economy, so that, Nigerian made goods can compete favorably with the imported goods and services, thereby reduce importation naturally instead of forcefully halt importation.
\end{abstract}

Keywords: Econometrics, Dynamic Multiple Linear Regression, GDP Per Capita, Explanatory Variable, Dependent Variable

\section{Introduction}

Nigeria is a mixed economy and emerging market, with expanding financial, service, communications, technology and entertainment sectors. Nigeria was ranked 26th in the world in terms of nominal GDP, 30th in 2013 before rebasing, 40th in 2005 and 52nd in 2000, and is the largest economy in Africa based on the rebased figures announced in 2014. It is also on track to become one of the top economies in the world by 2020. Despite its current underperforming form, manufacturing sector is still the third largest on the continent, and produces a large proportion of goods and services for the West African sub region. Nigeria, just of recent, changed its economic analysis to account for rapidly growing contributors to its GDP, such as telecommunications, banking, and film industry. As a result of this statistical revision, Nigeria has added $89 \%$ to its GDP, making it the largest African economy [1].

According to [2], in its revised World Economic Outlook (WEO), said that the Nigerian economy would now grow at a much slower pace than South Africa's, which is expected to grow at 0.1 percent in 2016. IMF recently published that growth projections were revised down substantially in subSaharan Africa, reflecting challenging macroeconomic conditions in its largest economies, which are adjusting to 
lower commodity revenues. Nigeria economic activity is now contracted in 2016, as its economy adjusted to foreign currency shortages because of lower oil receipts, low power generation, and weak investor confidence.

[3] Obstfeld (2016), IMF economic counselor and director of the research department, unveiling the revised outlook, said that the Brexit vote had thrown a spanner in economic growth. After the consultation of IMF with the Nigerian government on its plans for the 2016 fiscal year, set Nigeria's GDP growth at 2.3 percent showing that exports dropped about 40 percent in 2015, pushing the current account from a surplus of 0.2 percent of GDP to a deficit of 2.4 percent of GDP.

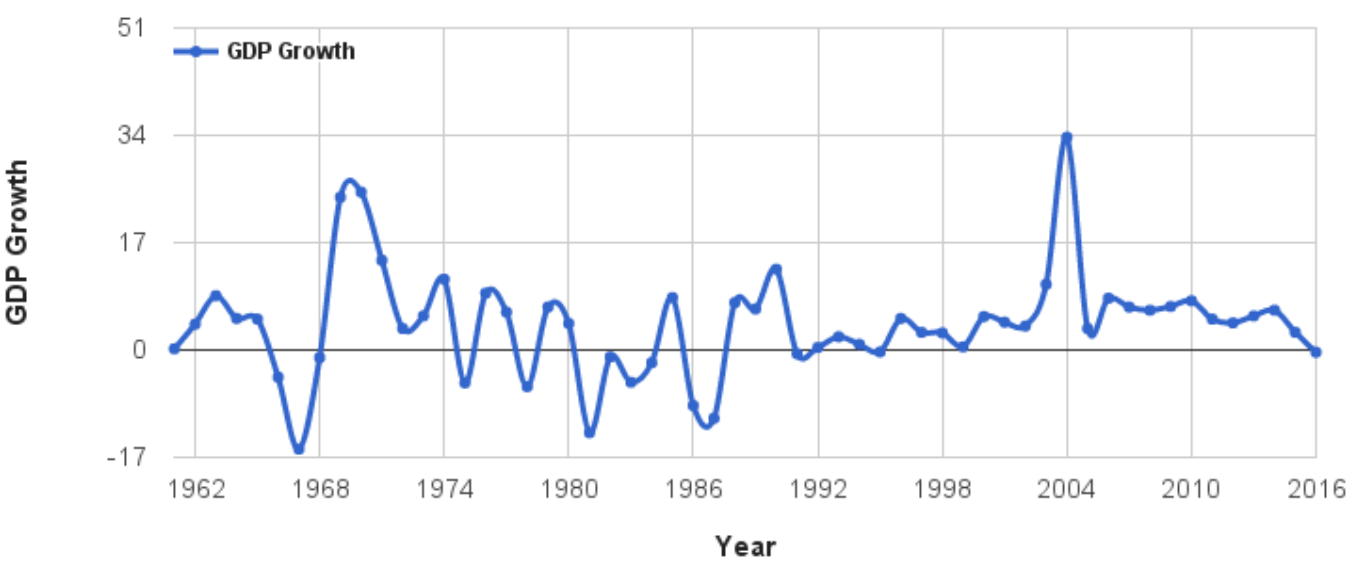

Figure 1. Nigeria's GDP growth rate (1961-2015).

Growth in 2016 declined further to 2.3 percent, with nonoil sector growth slowed down from 3.6 percent in 2015 to 3.1 percent in 2016 before recovering to 3.5 percent in 2017 as projected. Immediately the Nigerian economy shrunk by 0.36 percent in the first quarter of 2016 , and further decline in global economy, the IMF said that the growth reduction for Sub-Saharan Africa, driven by the difficult macroeconomic situation in its largest economies, Nigeria and South Africa, has a dramatic implication. Regional output growth in 2016 fell short of population growth, implying declining per capita incomes.

One of the greatest problems Nigeria is currently facing is the problem of recession, very poor economy situation, recording the lowest peak in cyclical variation. Nigeria has experience the period of boom (prosperity) in the past, recession and recovery. Today, Nigeria has gone through that cycle again and now in the period of recession. The big question now is how did Nigeria get to where we are today and what should stakeholders do, especially the policy makers to take us out from this predicament, when will Nigeria beginning to recover and what should be done for Nigeria to begin the recovery process? We know that one of the important economic growth indicator or one of the most important variables used in measuring economic wellbeing of any economy is the GDP of that nation but more importantly is the GDP per capita, which measure the real GDP of that nation.

So, GDP per capita (RGDP) is used as a proxy for measuring the economic wellbeing of Nigeria. So, knowing the direction at which this GDP per capita is tending and knowing the factors that can positively affect its growth, is a major concern to us as researchers. All these put together have triggered the writing of this paper. This research will not only help the government but will also help all the stakeholders in the intervention of the poor economic situation in the country.

However, this research is determined to examine the trend of Nigeria's economic growth as proxied by GDP per capita and other economic development variables for the period under review (1970 - 2015) using time plot; formulate a forecasting dynamic regression model for annual GDP Per Capita of Nigeria using data from 1970 - 2015; establish statements about predictors included in nation's GDP per Capita; carry out some diagnostic statistical testing on the assumption of general linear models, especially homoscedasticity and normality assumptions; and to recommend to stakeholders the appropriate steps to take to begin the recovery process of the economy presently in recession.

\section{Literature Review}

Econometrics is a branch of economics that is rapidly developing, which aims to give empirical content to economic relations. Econometrics may be defined in the broader sense as the application of mathematical and statistical methods in the analysis of economic data. [4].

Multiple Regression linear regression analysis predict the values of a dependent variable, $\mathrm{Y}$, given a set of $\mathrm{k}$ explanatory variables $\left(\mathrm{x}_{1}, \mathrm{x}_{2}, \ldots, \mathrm{x}_{\mathrm{k}}\right),[5]$. The multiple linear regression model is an extension of a simple linear regression model to include two or more explanatory variables in a predictive equation for a response variable. Multiple regression modelling is now a mainstay of statistical analysis in most fields due to it's power and flexibility. As you will quickly learn, it requires very little effort and sometimes even less thought to estimate very complicated models with large numbers of variables. This multiple linear regression model is a static model, which cannot abstract the dynamism of reality. 
Thus, dynamic multiple linear regression model is the one in which one of the independent variables is a lag dependent variable. This makes it dynamic because the last year value or last two years value depending on the lag is used to predict the present value, making the model more real as economic events are dynamic in nature.

The work of [6] examined the effect of exchange rate volatility on macroeconomic performance in Nigeria from 1986 to 2010. Their model formulated depicted Real GDP as the dependent variable while Exchange Rate (EXR), Balance of Payment (BOP) and Oil Revenue (OREV) are proxied as independent variables. They employed the Ordinary Least Squared (OLS) and Johansen co-integration estimation techniques to test for the short and long runs effects respectively. Their result using ADF test revealed that all variables are stationary. Their OLS results showed that OREV and EXR are positively related, while BOP is negatively related to GDP. Their further findings revealed oil revenue and balance of payment having negative effects on GDP while exchange rate volatility has positive effect on GDP in the long run. They recommended that graft should be tackled frontally in the oil sector, ensuring better utilisation of oil revenue, and adequate attention be paid to Agriculture and Solid mineral sectors and that the monetary authorities should pursue policies that would reduce inflation and ensure stability of Naira in World market.

The work of [7] focused on the impact of Monetary Policy on GDP. In their words, GDP, no doubt, is affected by the Monetary Policy of the state. They studied the research papers of various authors in this regard to prove the Hypothesis and after in depth analysis by applying Regression Analysis technique, they observed that the relationship between the two exists. They used the past 30 years data of Pakistan for driving the conclusion. Their study proved that the interest rate has weak relationship with GDP but the Growth in Money Supply greatly positively affects the GDP of an economy, obviously various unknown factors also affects the GDP. Growth in Money Supply has a huge impact on GDP. Their research study can further be used for developmental projects for the Growth of Economy, Quality improvements, Household production, the underground economy, Health and life expectancy, the environment, Political immunity and ethnic justice

[8] mentioned that foreign direct investment (FDI) has been a vital source of economic growth for Ghana. FDI brings in capital investment, technology and management knowledge needed for economic growth. Their paper aimed to study the relationship between FDI and economic growth in Ghana from 1980 to 2010 using time series data. The GDP, GDP growth rate, GNI, Manufacturing Value Added, External Debt Stock, Inflation, Trade, Industry Value added and Foreign Direct Investment net inflows as percent of GDP (FDI ratio). They used the simple ordinary least square (OLS) regressions and their empirical analysis was conducted by using the annual FDI and other variables over the periods 1980 to 2010. They used annual data from IMF, International Financial Statistics tables, published by
International Monetary Fund. The goal of their study was to determine the extent to which these variables are related. From this, they concluded that the independent variables GDP, GDPg, GNI, MVA, GDPc and TRA are all significant to explain the variation in FDI since their corresponding $\mathrm{p}$ values of the t-statistic are less than 5 percent and thus have an influence of FDI in Ghana. Their findings embraced practical implications for policy makers, government and investors.

[9] (2010) argued against a natural resource curse for human development. They found evidence that changes in human development, (1970 to 2005), proxied by changes in the Human Development Index, are positively and significantly correlated with natural resource abundance. While their results are consistent with those of other authors who have recently argued that natural resources do not adversely affect growth. They found strong evidence that natural resources have a positive effect on human development and particularly on its non-income dimensions. Their results from Latin America interactions showed that the positive impact of natural resources in this region is significantly smaller than that of the rest of the world. Their results contributed to a broader discussion on "resource curse" by showing that natural resources may be a blessing rather than a curse for human development, basically through its effects on education and health rather than income.

GDP per capita: GDP Per Capita is the ratio of gross domestic product (GDP) and midyear population. GDP is the sum of gross value added by all resident producers in the economy plus any product taxes and minus any subsidies not included in the value of the products. It's calculation is done without making deductions for depreciation of fabricated assets or for depletion and degradation of natural resources. Data are in current USD.

Food imports ( $\%$ of merchandise imports of a country): Food consists of the commodities such as (food and live animals), (beverages and tobacco), and (animal and vegetable oils and fats) and (oil seeds, oil nuts, and oil kernels). It is a proxy for food import as used in this paper, [10].

Official exchange rate (LCU per US\$, period average): Official exchange rate is the exchange rate determined by national authorities or the rate determined in the legally sanctioned exchange market. It is however calculated as an annual average based on monthly averages (local currency units relative to the USD).

Broad money (\% of GDP): Broad money is the sum of all currency outside banks; demand deposits other than those of the central government; the time, savings, and foreign currency deposits of resident sectors other than the central government; bank and traveller's checks; and other securities such as certificates of deposit and commercial paper.

Inflation, Consumer Prices (annual\%): Inflation as measured by the consumer price index (CPI) reflects the annual percentage change in the cost to the average consumer of acquiring a basket of goods and services that may be fixed or changed at specified intervals, such as yearly. The Laspeyres formula is generally used. Source: [11]. 
Total natural resources rents ( $\%$ of GDP): Total natural resources rents are the sum of oil rents, natural gas rents, coal rents (hard and soft), mineral rents, and forest rents. Source: [10].

Foreign direct investment, net inflows ( $\%$ of GDP): Foreign direct investment are the net inflows of investment to acquire a lasting management interest (10 percent or more of voting stock) in an enterprise operating in an economy other than that of the investor. It is the sum of equity capital, reinvestment of earnings, other long-term capital, and shortterm capital as shown in the balance of payments. This series shows net inflows (new investment inflows less disinvestment) in the reporting economy from foreign investors, and is divided by GDP. Source: [12].

\section{Dynamic Multiple Linear Regression}

The K-Variable linear equation model is used to study the relationship between a dependent variable and one or more independent variables. In this work, one of the independent variables is the lag of the dependent variable. This makes the model a bit different from the normal regression model, which is a static model. It is markovian in nature and dynamic. The problem with this model is that it can only be used to forecast the immediate future with timely data. Where data is not easily available, then the model will breakdown. The specification of a dynamic multiple regression model is given as

$$
y_{i}=\beta_{00}+\beta_{01} y_{i-p}+\beta_{1} x_{1}+\beta_{2} x_{2}+\cdots+\beta_{k} x_{k}+U_{i}, i=1, \ldots, n
$$

Where

$y$ is the dependent or explained variable

$x_{1}, \ldots, x_{k}$ are the independent or explanatory or regressor

variables as well as $y_{i-p}$, ( $p$ is the lag value)

$U$ is the random or disturbance or stochastic term

Matrix Formulation of the K-Variable Model

In matrix form

$$
\mathrm{Y}=\mathrm{X} \beta+\mathrm{U}
$$

Where

$$
Y=\left[\begin{array}{c}
y_{1} \\
y_{2} \\
\cdot \\
\vdots \\
y_{n}
\end{array}\right] X=\left[\begin{array}{cccc}
1 & x_{11} & \ldots & x_{1 k} \\
1 & x_{21} & \ldots & x_{2 k} \\
: & : & \ldots & . \\
\cdot & \cdot & \ldots & \cdot \\
1 & x_{n 1} & \ldots & x_{n k}
\end{array}\right] \beta=\left[\begin{array}{c}
\beta_{0} \\
\beta_{1} \\
\cdot \\
: \\
\beta_{k}
\end{array}\right] U=\left[\begin{array}{c}
u_{1} \\
u_{2} \\
\cdot \\
: \\
u_{n}
\end{array}\right]
$$

$\mathrm{Y}$ - We can pack all response values for all observations into a n-dimensional vector called the response vector.

$\mathrm{X}$ - We can pack all predictors into a $\mathrm{n} \mathrm{x} \mathrm{k}+1$ matrix called the design matrix. (Note the initial column of 1's. The reason for this will become clear shortly).

$\beta$ - We can pack the intercepts and slopes into a $\mathrm{k}+1$ dimensional vector called the slope vector,

$\mathrm{U}$ - We can pack all the errors terms into a n-dimensional vector called the error vector. [13], [14].

Assumptions of the Multiple Regression Model

To make any progress with the estimation of the vector of coefficients, $\beta$, using the DOLS, just like the ordinary least square (OLS), we must make some assumptions about how the observations in (1) have been generated.

Firstly, the model specifies a linear relationship between the response variable and the independent variables. It may be linear either in the original variables or after some suitable transformation. Secondly, there is no exact linear relationship among any of the independent variables. The columns of $\mathrm{X}$ are linearly independent. This assumption may fail if any of the independent variable already have strong correlation with the dependent variable, because the lag of the dependent variable is also an independent variable. Thirdly, the disturbance term is assumed to have conditional expected value zero $(0)$ at every observation.

$$
E[u]=\left[\begin{array}{c}
E\left(u_{1}\right) \\
E\left(u_{2}\right) \\
\cdot \\
: \\
E\left(u_{n}\right)
\end{array}\right]=\left[\begin{array}{c}
0 \\
0 \\
: \\
0
\end{array}\right]=0
$$

This implies that

$$
\mathrm{E}[\mathrm{Y}]=\mathrm{X} \beta
$$

The fourth assumption is that of spherical disturbance, which concerns the variance and the covariance of the disturbances.

$$
\operatorname{Var}\left(U_{i} / X\right)=\sigma^{2}, \text { for all } i=1, \ldots, n
$$

Note: Constant variance is called homoscedasticity and

$$
\operatorname{Cov}\left(U_{i}, U_{j} / X\right)=0, \forall i \neq j
$$

Note: This equation implies Non autocorrelation (i.e no serial correlation).

The two assumptions implies that

$$
E\left[U U^{1}\right]=\left[\begin{array}{cccc}
\sigma^{2} & 0 & \ldots & 0 \\
0 & \sigma^{2} & \ldots & 0 \\
: & : & \ldots & . \\
. & . & \ldots & . \\
0 & 0 & \ldots & \sigma^{2}
\end{array}\right]=\sigma^{2} I
$$

Note: Disturbances that meet the assumption of homoscedasticity and non-autocorrelation are sometimes called spherical disturbances. The fifth assumption is the exogenously generated data, $\mathrm{X}$ may be fixed or random, but it is generated by a mechanism that is unrelated to U. But in this case, it is related to $U$ because of the lag dependent variable. The disturbance is assumed to have conditional expected value zero $(0)$ at every observation. Finally, the sixth assumption is the normality assumption, which is convenient to assume that the disturbances are normally distributed with mean zero ( 0$)$ and constant variance $\left(\sigma^{2}\right)$. i.e $U \sim N\left(0, \sigma^{2}\right)$. The violation of at least one of these assumptions makes it useless to use OLS or DOLS, instead a weight need to be included to make it a DWLS or weighted 
least square (WLS). The nature of the weight is unknown before hand and it is also vital. Since, it is an application research; we use real life data and not simulated data, so we will select the best weight available in the Eviews 7 software.

\section{Research Methodology}

\subsection{Data Description}

The data used in this research are data on Gross Domestic Product Per Capita (RGDP), Total Import (IMP), Official Exchange Rate (OER), Broad Money (BMO), Inflation rate (INF), Total Natural Resources Rents (TNR), and Foreign Direct Investment (FDI) of Nigeria from 1970 to 2015. Data were obtained from World Bank database, National Bureau of Statistics (NBS) and Central Bank of Nigeria (CBN). The GDP per capital is lagged by one year and the lagged variable is derived by $R G D P 1_{t}=R G D P_{t+1}$.

Where $R G D P 1_{t}$ is the lagged variable of RGDP. The lagged RGDP, that is, RGDP1 is then used as one of the explanatory variables. All the variables are also normalized to remove the effect of time on them, so that the classical regression assumption can be satisfied.

$$
X_{i}=\frac{X_{\operatorname{Max}}-X_{t}}{X_{\operatorname{Max}}-X_{\operatorname{Min}}}
$$

Where $X_{i}$ is the ith normalized observation, $X_{t}$ is the actual observation at time $t, X_{\text {Man }}$ is the maximum observation of the variable, while $X_{\operatorname{Min}}$ is the minimum observation of the variable.

The newly normalized (transformed) variables are now NRGDP, NRGDP1, MIMP, NOER, NBMO, NINF, NTNR AND NFDI. The data is a time series data but has been normalized to take the time effect away from it, so than rather than using subscript $t$, we use subscript $i$.

\subsection{Model Specification}

Basically, the multiple linear regression models can be estimated using the Ordinary Least Square (OLS) but when some of the assumptions fail, we use other methods of estimation. For instance, if the variance of the residuals is not homogeneous (heteroscedasticty), meaning that one of the assumptions has failed, we make use of weighted least square (WLS).

Least Squares Estimation

There are number of different approaches to estimate the parameters of equation (2.1). The method of least squares has long been the most popular. Moreover, in the most cases in which some other estimation method is found to be preferable, least squares remains the benchmark approach, and often, the preferred method ultimately amounts to a modification of least squares.

Let $\hat{\beta}=\left(\hat{\beta}_{1}, \hat{\beta}_{2}, \ldots \hat{\beta}_{k}\right)$

Recall (2)

$$
Y=X \beta+U
$$

Where $\mathrm{U}$ denotes the column vector of $\mathrm{n}$ residuals That is

$$
U=Y-X \beta
$$

The sum of squared residuals is

$$
\begin{aligned}
\sum_{i=1}^{n} e_{i}^{2} & =e^{1} e \\
& =(Y-X \hat{\beta})^{1}(Y-X \hat{\beta}) \\
& =Y^{1} Y-2 \hat{\beta}^{1} X^{1} Y+\hat{\beta}^{1} X^{1} X \hat{\beta}
\end{aligned}
$$

(Note: $\hat{\beta}^{1} X^{1} Y$ is a scalar and thus equal to its transpose $\left.Y^{1} X \hat{\beta}\right)$

Differentiate $\mathrm{e}^{1} \mathrm{e}$ with rspect to $\hat{\beta}$ and equate it to zero, we have

$$
\begin{gathered}
d e^{1} e / d \hat{\beta}=-2 X^{1} Y+2 \hat{\beta} X^{1} X=0 \\
2 \hat{\beta} X^{1} X=2 X^{1} Y \\
\hat{\beta}=\left(X^{1} X\right)^{-1} X^{1} Y
\end{gathered}
$$

Equation (16) is called the least squares estimate.

Test for Heteroscedasticity

One of the assumptions is that the disturbances $U_{i}$ in the population regression function are homoscedastic i.e have the same variance.

$$
\left.\begin{array}{c}
E\left(U U^{\prime}\right)=\sigma^{2} I_{n} \\
E\left(U^{2}{ }_{i}\right)=\sigma^{2}, \text { for all } i \\
E\left(U_{i} U_{j}\right)=0, \text { for all } i \neq j
\end{array}\right\} \text { spherical disturbance }(17)
$$

When this assumption breaks down it results in Heteroscedasticity i. e unequal variance.

The presence of Heteroscedasticity makes t-test unreliable and standard error estimates will be large even if the coefficients are linear, unbiased and consistent.

One of the methods of detecting Heteroscedasticity is the Spearman's Rank Correlation method. This is an easy approach that can be applied to both small and large samples.

If

$$
Y=\beta_{1}+\beta_{2} X_{i}+U
$$

Regress $\mathrm{Y}$ on $\mathrm{X}$; obtain the residual $e_{1}$ and rank the $e_{1}{ }^{\prime} s$ in ascending or descending order. Ignore the signs; and compute the rank correlation coefficient

$$
r_{e . x}=1-\frac{6 \sum D_{i}^{2}}{n\left(n^{2}-1\right)}
$$

Where

$D_{i}$ is the difference between the rank of corresponding pairs of $X$ and $e, n$ is the number of observations in the sample. A high rank correlation coefficient suggests the presence of Heteroscedasticity.

The problem of Heteroscedasticity can be remedy by (i) Weighted Least Squares (ii) Maximum Likelihood Method (iii) Transform the data and Perform regression again (iv) Use different Functional Form. In this research, we used weighted least square (WLS). 


\section{Harvey}

The [15] test for heteroscedasticity is similar to the Breusch-Pagan-Godfrey test. However Harvey tests a null hypothesis of no heteroscedasticity against heteroscedasticity of the form of $\sigma_{t}^{2}=\exp \left(z_{t}^{\prime} \alpha\right)$, where, again $z_{t}$, is a vector of independent variables. To test for this form of heteroscedasticity, an auxiliary regression of the log of the original equation's squared residuals on $\left(1, z_{t}\right)$ is performed. The LM statistic is then explained sum of squares from the auxiliary regression divided by $\varphi(0.5)$, the derivative of the $\log$ gamma function evaluated at 0.5 . This statistic is distributed as a $\chi^{2}$ with degrees of freedom equal to the number of variables in $\mathrm{z}$.

Dynamic Weighted Least Squares (DWLS)

Let us assume that we have heteroscedasticity of known form, where the conditional error variances are given by $\sigma_{i}^{2}$. The presence of heteroscedasticity will not affect the bias or consistency properties of DOLS or OLS estimates, but DOLS and OLS are no longer efficient and conventional estimates of the coefficient standard errors are not valid.

Suppose the variances $\sigma_{i}^{2}$ are known up to a positive scale factor, you may use DWLS or WLS to obtain efficient estimates that support valid inference. The WLS estimator for $\beta$ minimizes the weighted sum of squares residuals with respect to the m-dimensional vector of parameters $\beta$, where the weights are proportional to the inverse conditional variances. Equivalently, you may estimate the regression of the square root weighted transformed data. By default, in
Eviews, all observations are given equal weight in estimation. It is possible to instruct EViews to estimate your specification with estimated GLS weights using the combo box labeled Weights.

If we select Cross section weights, EViews estimates a feasible GLS specification assuming the presence of crosssection heteroscedasticity. If you select Cross-section SUR, EViews estimates a feasible GLS specification correcting for both cross-section heteroscedasticity and contemporaneous correlation. Similarly, Period weights allows for period heteroscedasticity, while Period SUR corrects for both period heteroscedasticity and general correlation of observations within a given cross-section. Note that the SUR specifications are each examples of what is sometimes referred to as the Parks estimator, [16].

\section{Empirical Data Analysis}

The data collected for this research is presented in the abridged Table 1 below and depicted in Figure 2 to Figure 8 are Nigeria microeconomic and economic growth data from 1070 to 2015.

The actual data in Table 1 have different units. Some are in USD, some are in Naira, some are in percentage while some are rates. In order to make the data be uniform, we normalized the data so that all the dataset fall between 0 and 1. It is the normalized data that was used for the analysis. The normalized data is shown in Table 4.2.

Table 1. Actual Data on Economic Growth and Microeconomic Variables 1970-2015.

\begin{tabular}{|c|c|c|c|c|c|c|c|}
\hline Year & RGDP(US\$) & IMP (N) & OER & BMO (N) & INF & TNR & FDI (N) \\
\hline 1970 & 223.5068 & $1,004,900,000$ & 0.714286 & $979,300,000$ & 13.7571 & 4.5392 & $205,000,000.00$ \\
\hline 1971 & 159.8115 & $1,414,100,000$ & 0.712855833 & $1,041,900,000$ & 15.9991 & 10.7502 & $286,000,000.00$ \\
\hline 1972 & 208.6445 & $1,301,600,000$ & 0.657894999 & $1,204,200,000$ & 3.4576 & 10.0879 & $305,000,000.00$ \\
\hline 1973 & 251.5179 & $1,880,600,000$ & 0.657894999 & $1,370,100,000$ & 5.4027 & 14.6432 & $373,000,000.00$ \\
\hline 1974 & 401.6786 & $2,856,000,000$ & 0.630282046 & $2,592,200,000$ & 12.6744 & 36.2687 & $257,000,000.00$ \\
\hline 1975 & 437.0121 & $5,238,800,000$ & 0.615501553 & $4,035,100,000$ & 33.9642 & 24.8585 & $470,120,000.00$ \\
\hline . & . & . & . & . & . & . & . \\
\hline . & . & . & . & . & . & . & . \\
\hline . & . & . & . & . & . & . & . \\
\hline 2013 & $2,979.8442$ & $10,530,447,520,000$ & 157.311225 & $17,307,365,426,666$ & 8.4758 & 15.5231 & $5,562,873,605.74$ \\
\hline 2014 & $3,203.2443$ & $11,222,115,570,000$ & 158.5526417 & $18,173,830,311,616$ & 8.0574 & 12.4889 & $4,655,849,169.78$ \\
\hline 2015 & $2,640.2907$ & $10,269,901,020,000$ & 192.4405244 & $21,953,991,580,000$ & 9.0177 & 4.7000 & $3,064,170,000.00$ \\
\hline
\end{tabular}

Source: World Bank Databank, 2016

Table 2. Normalized Data.

\begin{tabular}{|c|c|c|c|c|c|c|c|c|}
\hline Year & NRGDP & NRGDP1 & NIMP & NOER & NBMO & NINF & NTNR & NFDI \\
\hline 1970 & 0.9769 & 1.0105 & 1.0000 & 0.9991 & 1.0000 & 0.8515 & 1.0023 & 0.9015 \\
\hline 1971 & 0.9978 & 0.9769 & 1.0000 & 0.9991 & 1.0000 & 0.8192 & 0.9120 & 0.8930 \\
\hline 1972 & 0.9818 & 0.9978 & 1.0000 & 0.9994 & 1.0000 & 1.0000 & 0.9217 & 0.8910 \\
\hline 1973 & 0.9677 & 0.9818 & 1.0000 & 0.9994 & 1.0000 & 0.9720 & 0.8555 & 0.8839 \\
\hline 1974 & 0.9185 & 0.9677 & 0.9999 & 0.9996 & 0.9999 & 0.8672 & 0.5411 & 0.8960 \\
\hline 1975 & 0.9069 & 0.9185 & 0.9997 & 0.9996 & 0.9999 & 0.5603 & 0.7069 & 0.8738 \\
\hline . & . & . & . & . & . & . & . & . \\
\hline . & . & . & . & . & . & . & . & . \\
\hline . & . & . & . & . & . & . & . & . \\
\hline 2013 & 0.0732 & 0.1519 & 0.2300 & 0.1831 & 0.2117 & 0.9277 & 0.8427 & 0.3422 \\
\hline 2014 & 0.0000 & 0.0732 & 0.1794 & 0.1766 & 0.1722 & 0.9337 & 0.8868 & 0.4369 \\
\hline 2015 & 0.1846 & 0.0000 & 0.2491 & 0.0000 & 0.0000 & 0.9199 & 1.0000 & 0.6030 \\
\hline
\end{tabular}




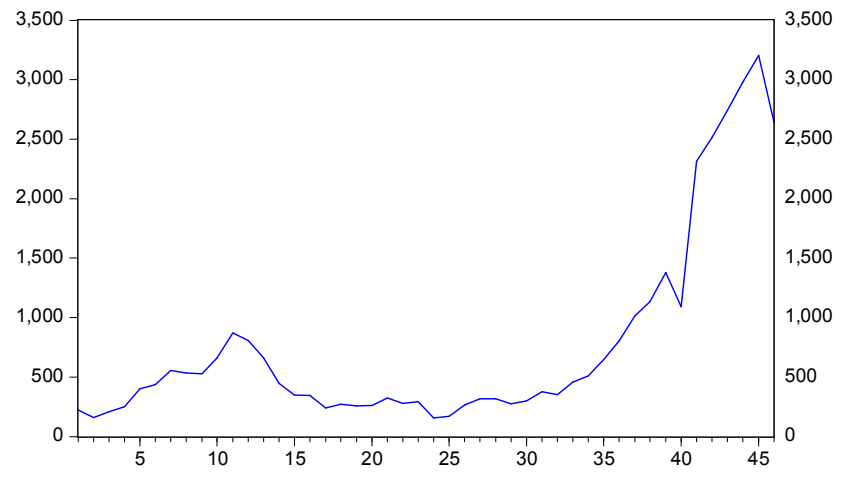

Figure 2. GDP Per Capita (in USD).

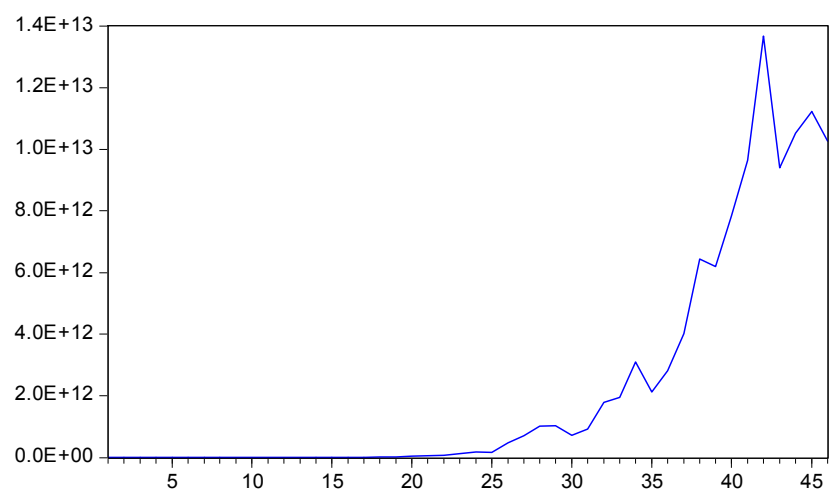

Figure 3. Imports of Goods \& Services (in Naira).

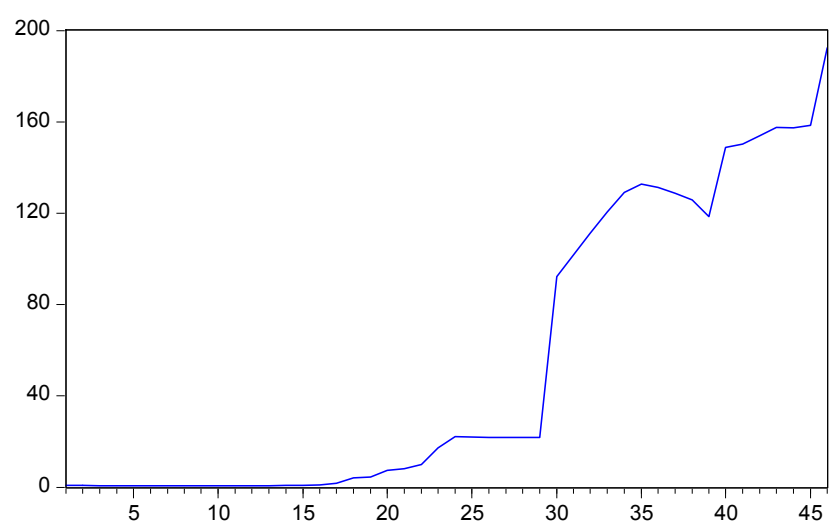

Figure 4. Official Exachange Rate (Naira per USD).

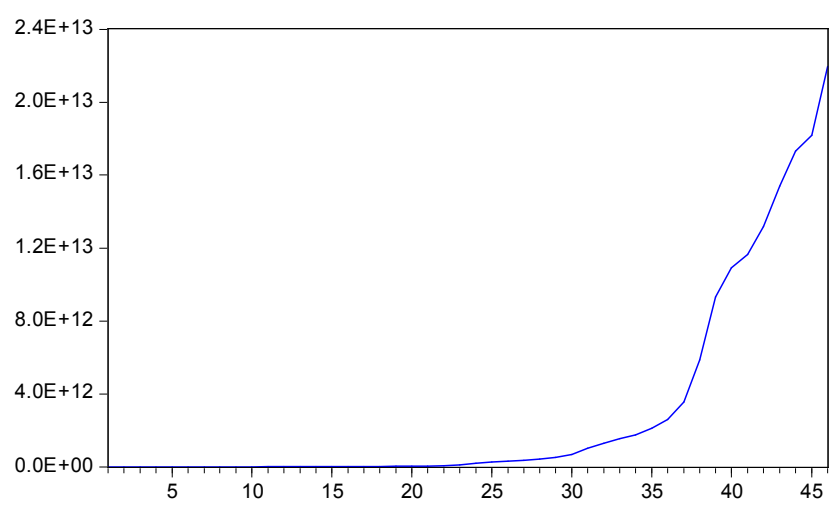

Figure 5. Broad Money (in Naira).

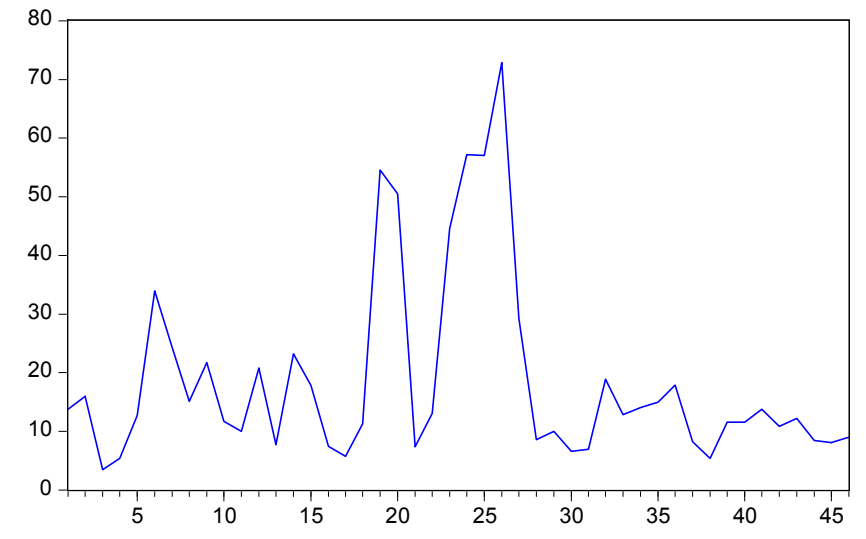

Figure 6. Inflation, Consumer Price (annual\%).

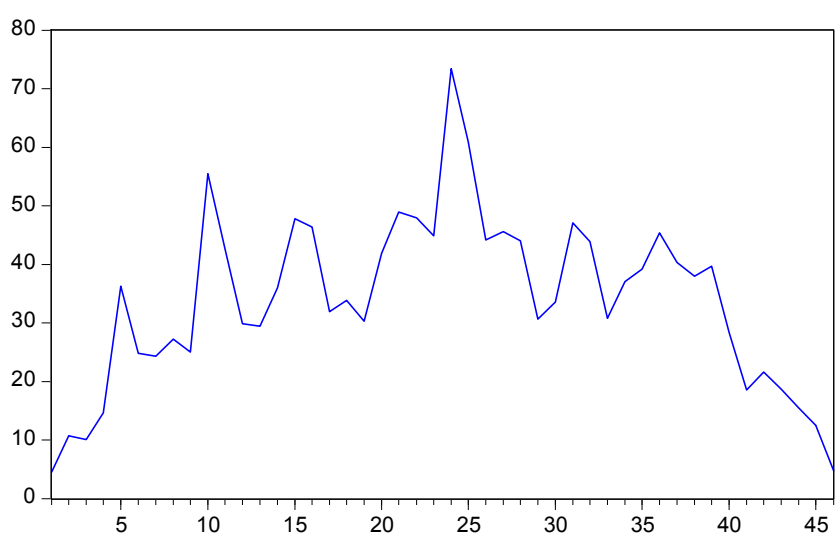

Figure 7. Total Natural Resources, Rents (\% of GDP).

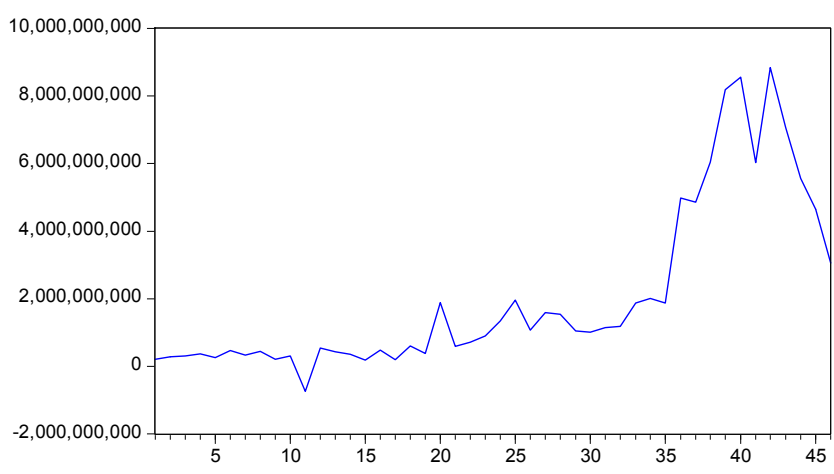

Figure 8. Foreign Direct Investment, Net Inflows (BoP, current USD).

The time plots depict that the general direction of all the variables plotted is upward, showing trend except for inflation rate and total natural resources. Also, is also declining in recent times but the variable that declined sharply, which is obvious, is foreign direct invest. 
Table 3. Descriptive Statistics.

\begin{tabular}{|c|c|c|c|c|c|c|c|}
\hline Statistic & RGDP & IMP & OER & ВMO & INF & TNR & FDI \\
\hline Mean & 767.32 & $2.32 \mathrm{E}+12$ & 54.48596 & $3.07 \mathrm{E}+12$ & 18.65320 & 33.89209 & $2.07 \mathrm{E}+09$ \\
\hline Median & 419.35 & $1.50 \mathrm{E}+11$ & 19.59143 & $1.64 \mathrm{E}+11$ & 12.77549 & 34.90710 & $1.03 \mathrm{E}+09$ \\
\hline Maximum & 3203.24 & $1.37 \mathrm{E}+13$ & 192.4405 & $2.20 \mathrm{E}+13$ & 72.83550 & 73.48844 & $8.84 \mathrm{E}+09$ \\
\hline Minimum & 153.08 & $1.00 \mathrm{E}+09$ & 0.546781 & $9.79 E+08$ & 3.457650 & 4.539242 & $-7.39 \mathrm{E}+08$ \\
\hline Std. Dev. & 823.95 & $3.81 \mathrm{E}+12$ & 65.12414 & $5.77 \mathrm{E}+12$ & 16.23591 & 14.67788 & $2.54 \mathrm{E}+09$ \\
\hline Skewness & 1.84 & 1.603770 & 0.667586 & 1.933593 & 1.815698 & 0.023773 & 1.428569 \\
\hline Observations & 46 & 46 & 46 & 46 & 46 & 46 & 46 \\
\hline
\end{tabular}

It can be seen from Table 3 that for the period under review, the average GDP per capita is $\$ 767.32$, the average import of goods and service is $\$ 2.32$ trillion, the average Official Exchange Rate (Naira per USD) is 154.49 , the average broad money is $\$ 3.07$ trillion, the average inflation rate $(\mathrm{CPI})$ is 18.65 , the total natural resources, rent $(\%$ of GDP) is 33.89 and the foreign direct investment, net inflows is $\$ 2.07$ billion. It is also evident that the GDP per capita minimum ever attained for the period under review is $\$ 153.08$ and the maximum ever attained is $\$ 3203.24$. The standard deviation for the period dataset for GDP per capita is 823.95 with skewness and kurtosis of 1.84 and 5.09 respectively.

Table 4. Model Estimation Using Dynamic Ordinary Least Squares.

\begin{tabular}{lllll}
\hline Variable & Coefficient & Std. Error & t-Statistic & P-value \\
\hline NRGDP1 & 0.572187 & 0.133802 & 4.276364 & 0.0001 \\
NIMP & 0.578255 & 0.161074 & 3.589985 & 0.0009 \\
NOER & -0.061284 & 0.055541 & -1.103414 & 0.2766 \\
NBMO & -0.011602 & 0.174773 & -0.066381 & 0.9474 \\
NINF & -0.025786 & 0.040110 & -0.642873 & 0.5241 \\
NTNR & -0.005261 & 0.044805 & -0.117418 & 0.9071 \\
NFDI & -0.100558 & 0.084106 & -1.195609 & 0.2391 \\
R-squared & 0.952460 & Mean dependent var & 0.798613 \\
Adjusted R-squared & 0.945146 & S.D. dependent var & 0.270133 \\
S.E. of regression & 0.063268 & Akaike info criterion & -2.543613 \\
Sum squared resid & 0.156110 & Schwarz criterion & -2.265342 \\
Log likelihood & 65.50310 & Hannan-Quinn criter. & -2.439371 \\
Durbin-Watson stat & 2.492383 & & \\
\hline
\end{tabular}

Using the DOLS, base on the probability values in Table 4, only the lagged dependent variable used as an explanatory variable (NRGDP1) and official exchange rate are statistically significant at $5 \%$ level. This means that a better functional form will be needed to generate estimates that are more robust. This led to the use of DWLS. The result of the dynamic weighted least square is given in Table 5 .

Table 5. Model Estimation Using Dynamic Weighted Least Squares.

\begin{tabular}{lllll}
\hline Variable & Coefficient & Std. Error & t-Statistic & P-value \\
\hline NRGDP1 & 0.6367 & 0.134883 & 4.720476 & 0.0000 \\
NIMP & 1.3494 & 0.190746 & 7.074366 & 0.0000 \\
NOER & -0.1536 & 0.063439 & -2.421892 & 0.0202 \\
NBMO & -0.6554 & 0.213883 & -3.064115 & 0.0039 \\
\hline
\end{tabular}

\begin{tabular}{lllll}
\hline Variable & Coefficient & Std. Error & t-Statistic & P-value \\
\hline NTNR & -0.0806 & 0.027799 & -2.899661 & 0.0061 \\
NFDI & -0.1838 & 0.081379 & -2.258290 & 0.0296 \\
& \multicolumn{2}{l}{ Weighted } & Statistics & \\
R-squared & 0.971824 & Mean dependent var & 0.713701 \\
Adjusted R-squared & 0.968212 & S.D. dependent var & 0.190798 \\
S.E. of regression & 0.065959 & Akaike info criterion & -2.475996 \\
Sum squared resid & 0.169674 & Schwarz criterion & -2.235107 \\
Log likelihood & 61.70990 & Hannan-Quinn criter. & -2.386195 \\
Durbin-Watson stat & 2.279005 & Weighted mean dep. & 0.641204 \\
\hline
\end{tabular}

The dynamic weighted least square, using NIMP weighting series and average scaling variance, Table 5 shows that all the variables are significantly related to NRGDP at $5 \%$ level. This particular functional form will be adopted. Note that the NINF has been removed from the model; since it was the variable that shows the least relationship with NRGDP. The NIMP is used for the weighting series in the new model. The table shows that a unit increase in NRGDP1 will lead to a 0.6367 increase in NRGDP provided other explanatory variables remain constant. A unit increase in NIMP will lead to a significant increase in NRGDP by 1.3494; a unit increase in NOER will lead to a significant decrease in NRGDP by 0.1536 , provide other explanatory variables are kept constant. If NBMO increases by 1 unit, then NRGDP will dencrease by 0.6554 provided other explanatory variables are remain constant. If NTNR increases by 1 unit, then NRGDP will decrease by 0.0806 provided other explanatory variables remain constant and if NFDI increases by 1 unit, then NRGDP will decrease by 0.1838 provided other explanatory variables remain constant.

Table 5 also shows that $97.2 \%$ of the total variation in NRGDP can be explained by the variations in NRGDP1, NIMP, NOER, NBMO, NTNR and NFDI, while the remaining $2.8 \%$ could be explained by other variables other than the ones used in formulating this model.

Table 6. Heteroscedasticity Test Using Harvey.

\begin{tabular}{llll}
\hline F-statistic & 1.831297 & Prob. F(6,38) & 0.1189 \\
Obs*R-squared & 10.09334 & Prob. Chi-Square(6) & 0.1208 \\
\hline
\end{tabular}

The null hypothesis states that there is no heteroscedasticity as against the alternative hypothesis that there is heteroscedasticity $\left(\mathrm{H}_{0}\right.$ : Equal variances vs $\mathrm{H}_{1}$ : Unequal variances). Since we cannot reject the null hypotheses because the test is not significant (P-value $(0.1189$ or 0.1208$)>0.05)$. It is therefore concluded that there is little or no presence of heteroscedasticity. 


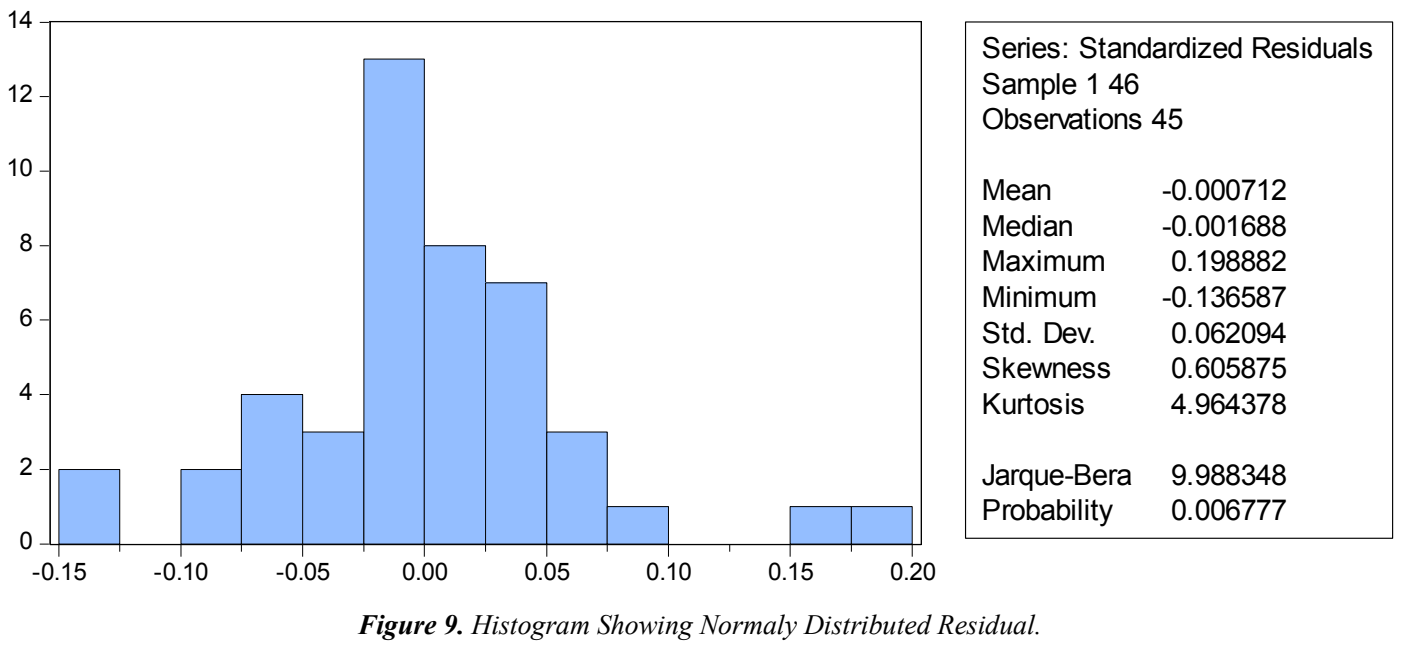

The normality test shows that the mean is approximately zero $(0)$ and with standard deviation 0.062 . The coefficient of skewness is 0.605875 and the kurtosis is 4.964 . However, there are gaps in the histogram but it is approximately normal. The residual graph in the diagram below depicts that the residual oscillate about zero. This implies that there is no systematic change in the mean and variance of the residual.

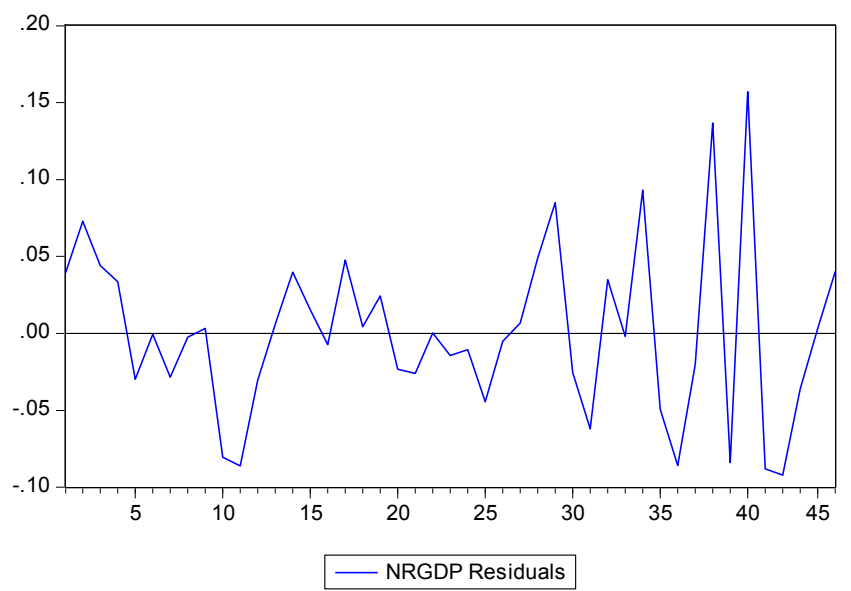

Figure 10. Time Plot Showing Normaly Distributed Residual.

\section{Conclusion and Recommendations}

\subsection{Conclusion}

The data collected from World Bank Database for Nigeria from 1970 to 2015, which were summarized and analyzed in order to achieve the objectives of this research, are hereby concluded as follows:

The time plot shows that GDP per capital, import of goods and services and foreign direct investment respectively depict upward trend but significantly dropped in 2015. However, official exchange rate and broad money show continuous upward trend. Inflation rate and total natural resources

The model fitted for predicting and forecasting GDP per Capita is such that increase in import of food and services will also lead to a significant increase in GDP per Capita; while on the other hand, increase in official exchange rate, broad money, total natural resources and foreign direct investment will lead to a significant decrease in GDP per Capita. This implies that a fall in importation of goods and services may lead to a fall in GDP per Capita. This is because Nigeria economy has been design to depend on importation of goods and services.

We observed that that $71.1 \%$ of the total variation in GDP per capita of Nigeria can be explained by the variations in OER-Official Exchange Rate (LCU Per US\$, Period Average), BM-Broad Money (\% of GDP), INF-Inflation, GDP deflator (Annual\%), TNR-Total Natural Resources Rents ( $\%$ of GDP) and FDI-Foreign Direct Investment, Net Inflows ( $\%$ of GDP), while the remaining $28.9 \%$ could be explained by other variables other than the ones used. Statistically, the assumption that the residual have equal variance (homoscedasticity) must be satisfied before least square models can be applied. The variable dropped and the dynamic weighted least square applied has taken care of multicollinearity and heteroscedasticity respectively in the residual. Also, the residual must be normally distributed, which we also achieved. It is there concluded that the model be used in predicting and forecasting Nigeria economic situation.

\subsection{Recommendation}

Based on the conclusion reached, it is recommended that if the economy of Nigeria wants to experience real growth, then importation of goods and services must not be discouraged. However, policies should be put in place to regulate the type of goods and services imported into the country. If Nigeria decides to stop importation, then we should not expect any growth for a long time until the system is completed adjusted to accommodate the change. Another advice is that Nigerians investors and other investors should be encouraged to produce competitive goods in Nigeria that can compete favourably with the imported ones. If this is achieved, even without closing our borders, naturally, consumers will be attracted to home made goods and services rather than imported ones. 
In addition, policy makers should try to reduce broad money and official exchange rate because decreasing these variables will significantly in GDP per Capita, which is a proxy to economic growth. Note that trying to increase exchange rate (naira per a dollar) can never increase GDP per Capita, rather it will decrease it significantly. The same goes for inflation rate. If we expect any positive change in the economy, then the Central Bank of Nigeria should be engaged in policy formation that will help in reducing exchange rate and inflation rate, and not to stop importation but rather re-strategize to accommodate imported goods and services. However, if the policy of closing the borders is the best solution, then Nigeria must be ready to endure slow economic growth because GDP per capita will not grow as expected and the masses will not understand. If the government is sensitive to the people, then this is not the right time to close the borders, rather, it is time to fix our power sector, and make the environment suitable for production of goods and services so that our local products can be competitive. If the power sector problem is solved, then an average Nigeria will become a producer of goods and services.

More so, Nigeria needs to balance imports with their exports. Nigeria economy is affected seriously by low exports, which can be attributed to low crude oil prices and low crude exports. So, if the energy sector is viable and there is power to run the economy, then Nigeria can depend on home made goods and services, their by reducing importation naturally and not to close boarder.

\section{References}

[1] Wikipedia (2016): http://en.wikipedia.org/wiki/Economy_of_Nigeria.

[2] International Monetary Fund (IMF), (2016). World Economic Outlook (WEO).

[3] Obstfeld, M. (2016). A Spanner in the Works: An Update to the World Economic Outlook. Posted on July 19, 2016 by iMFdirect. Available at www.blog-imfdirect.imf.org.
[4] Samuelson, P. A., Koopmans, T. C. and Stone, J. R. N. (1954). Report of the evaluative committee for Econometrical. Econometrical 22, 141-6.

[5] Tranma, M. and Elliot, M. (2012). Multiple Linear Regression, Carthie Marsh Centre for Census and Survey Research. Pp 1.

[6] Azeez, B. A, Kolapo, F. T and Ajayi, L. B. (2012). Effect Of Exchange Rate Volatility On Macroeconomic Performance In Nigeria. Interdisciplinary Journal of Contemporary Research in Business. Vol 4, no 1.

[7] Hameed, I. and Ume, A. (2011). Title: Impact of Monetary Policy on Gross Domestic Product (GDP). Institute of Interdisciplinary Business Research. Pages: 1348-1361.

[8] Antwi, S., Mills, E. F. E. A., Mills, G. A. and Zhao, X. (2013). Impact of foreign direct investment on economic growth: Empirical evidence from Ghana. International Journal of Academic Research in Accounting, Finance and Management Sciences. Vol. 3, No.1, January 2013, pp. 18-25.

[9] Pineda, J. and Rodríguez, F. (2010). Curse or Blessing? Natural Resources and Human Development. United Nations Development Programme Human Development Reports Research Paper. June 2010.

[10] World Bank Databank sources (2016): International Financial Statistics and data files and OECD GDP estimates. Balance of Payments databases, International Debt Statistics. IMF, World Economic Outlook, October 2016.

[11] International Monetary Fund (IMF), (2016). International Financial Statistics and data files.

[12] International Monetary Fund (IMF), (2016). International Financial Statistics and Balance of Payments databases.

[13] Olubusoye, E. O. (2013) - Econometrics Model. Centre for Econometric and Allied Research at Ibadan.

[14] Alaba O. O. (2012). "Regression and Analysis of Variance Note". Statistics Department, University of Ibadan, Oyo State.

[15] Harvey, A. C (1976). Estimating Regression Models with Multiplicative Heteroscedasticity, Econometrica, 44 (1976), Pp 461-466.

[16] Baltagi, B. H. (1980). On seemingly unrelated regressions with error components, Econometrica 48, Pp 1547-1551. 